Personalidade Acadêmica Homenageada:

Carlos Aurélio Mota de Souza (Universidade Ibirapuera - UNIB)

\title{
A INSTITUIÇÃO DA POLÍTICA DE COMPLIANCE COMO FORMA DE PREVENÇÃO AO ASSÉDIO MORAL NO AMBIENTE DE TRABALHO
}

\section{THE INSTITUTION OF THE COMPLIANCE POLICY AS A FORM OF PREVENTION TO THE MORAL HARASSMENT IN THE WORK} ENVIRONMENT

RODRIGO THOMAZINHO COMAR

Mestrando em Direito Empresarial e Cidadania pela Faculdade de Direito do Centro Universitário Curitiba (Unicuritiba). Pós-graduado em Direito Processual Civil pela Pontifícia Universidade Católica do Paraná (PUCPR) em 2002. Graduado pela Universidade Estadual de Londrina em 2000. Membro do Grupo de Pesquisa Reforma trabalhista: os valores sociais do trabalho e da livre iniciativa. Email: rodrigoadvoc@hotmail.com.

\section{RESUMO}

Trata o presente artigo do estudo da política de compliance como instrumento para viabilizar a prática de medidas responsáveis e éticas nas empresas, servindo como forma para preservação de um ambiente de trabalho sadio e hígido no tocante às relações de trabalho que se estabelecem. O referido instrumento ganha importância em relação ao seu caráter preventivo no combate ao assédio moral, tendo em vista que tal fenômeno é responsável por afastamentos e redução de produtividade de empregados, além de degradar o ambiente de trabalho e desgastar as relações laborais. Desta maneira, como ferramenta de prevenção a tais comportamentos e visando atender o objetivo de implementação de práticas responsáveis e éticas, será abordado em que medida é possível concretizar tais políticas de conformidade tudo com intuito do escopo da ética empresarial. 
Personalidade Acadêmica Homenageada:

Carlos Aurélio Mota de Souza (Universidade Ibirapuera - UNIB)

PALAVRAS-CHAVE: Compliance; Relações de trabalho; Meio ambiente do trabalho; Ética empresarial.

\begin{abstract}
It deals with the present article of the study of the compliance policy as an instrument to make feasible the practice of responsible and ethical measures in the companies, serving as a way to preserve a healthy and healthy work environment with regard to the working relationships that are established. This instrument gains importance in relation to its preventive character in the fight against moral harassment, considering that this phenomenon is responsible for withdrawals and reduction of employee productivity, besides degrading the work environment and depleting labor relations. In this way, as a tool to prevent such behaviors and aiming to meet the goal of implementing responsible and ethical practices, it will be approached to what extent it is possible to concretize such compliance policies all with the purpose of the scope of business ethics.
\end{abstract}

KEYWORDS: Compliance; Work Relationships; Work Environment; Business Ethics.

\title{
INTRODUÇÃO
}

O estudo em questão tem por objetivo a análise da política de compliance, iniciando por sua conceituação, suas formas e sua abrangência, sendo o referido tema considerado ainda em relação ao seu âmbito de práticas e ações adotadas por empresas na busca do objetivo de implementar condutas responsáveis e éticas tanto para os gestores como para os empregados.

Não é demais destacar o fato de que medidas de conformidade vem ganhando destaque e importância em relação ao âmbito empresarial tendo em vista a necessidade de combate e coação a atos que possam macular a imagem e o clima 
Personalidade Acadêmica Homenageada:

Carlos Aurélio Mota de Souza (Universidade Ibirapuera - UNIB)

organizacional, funcionamento como instrumento de prevenção a tais condutas, passando pela abordagem, ainda que rápida, pela norma positivada nas leis anticorrupção e de proteção a concorrência.

Feitas as considerações acerca de tal instrumento, será necessário abordar as questões relacionadas ao meio ambiente do trabalho, também com sua conceituação e destaque para sua amplitude, tendo em vista ser essa a seara em que serão analisadas em que medidas as práticas de conformidade podem ser aplicadas visando afastar ou mitigar atos relacionados ao assédio moral nas organizações empresariais.

Por também guardar relação com o tema, o estudo será voltado para o meio ambiente do trabalho e do assédio moral, temas esses que ganham importância por suas diversas facetas quando do desenvolvimento nas relações de emprego e trabalho, acabando o assédio por denegrir a imagem e o clima organizacional, além de causar malefícios também para produção e rendimento dos empregados, posto que afeta a saúde e a sanidade destes.

Desta maneira, após a abordagem dos três temas do presente estudo, será necessário abordar em que medida pode a instituição de políticas de compliance colaborar no combate das práticas de assédio moral e, de forma reflexa, contribuir na manutenção de um ambiente de trabalho hígido e sadio, preservando o direito dos empregados e a imagem da organização empresarial.

Por fim, necessário esclarecer que a investigação será feita por meio de abordagem teórica, o qual será feita pela pesquisa bibliográfica sobre o tema, além do estudo de conceitos e teorias que visam explicar a relação e a influência de tal política organizacional nas empresas com intuito de averiguar quais os efeitos e reflexos da instituição das medidas de conformidade no combate do assédio moral. 
Personalidade Acadêmica Homenageada:

Carlos Aurélio Mota de Souza (Universidade Ibirapuera - UNIB)

\section{AMBIENTE DE TRABALHO E O ASSÉdiO MORAL: ALGUMAS CONSIDERAÇÕES}

O meio ambiente do trabalho decorre de garantia e proteção constitucional, podendo ser considerado como direito fundamental de todo trabalhador a prestação de serviços em meio que seja saudável e hígido, sendo obrigação do empregador zelar por tais condições.

Assim, a proteção do meio ambiente, entendido como direito fundamental encontra respaldo nos artigos $7^{\circ}$, inciso XXII, 200, inciso VIII e 225, todos da Constituição Federal ${ }^{1}$, sendo essa norma fundamental e que se enquadra, portanto, como garantia, do qual abrange também o âmbito trabalhista.

O referido sistema ganhou estruturação infraconstitucional com a edição da Lei 6.938, de 31 de agosto de 1981, em que se estabeleceu a Política Nacional do Meio Ambiente do qual se extrai, no inciso I do seu artigo $3^{\circ}$, o seu conceito como sendo "[...] meio ambiente, o conjunto de condições, leis, influências e interações de ordem física, química e biológica, que permite, abriga e rege a vida em todas as suas formas $[\ldots] "$.

Além do conceito, a norma, prevê, ainda, formas de degradação deste, o quais podem ser citadas as condutas referentes a atos que:

[...] a) prejudiquem a saúde, a segurança e o bem-estar da população; b) criem condições adversas às atividades sociais e econômicas; c) afetem desfavoravelmente a biota; d) afetem as condições estéticas ou sanitárias do meio ambiente; e) lancem matérias ou energia em desacordo com os padrões ambientais estabelecidos.

\footnotetext{
1 Art. $7^{\circ}$ São direitos dos trabalhadores urbanos e rurais, além de outros que visem à melhoria de sua condição social: [...] XXII - redução dos riscos inerentes ao trabalho, por meio de normas de saúde, higiene e segurança; Art. 200. Ao sistema único de saúde compete, além de outras atribuições, nos termos da lei: [...] VIII - colaborar na proteção do meio ambiente, nele compreendido o do trabalho. Art. 225. Todos têm direito ao meio ambiente ecologicamente equilibrado, bem de uso comum do povo e essencial à sadia qualidade de vida, impondo-se ao Poder Público e à coletividade o dever de defendêlo e preservá-lo para as presentes e futuras gerações.
} 
Personalidade Acadêmica Homenageada:

Carlos Aurélio Mota de Souza (Universidade Ibirapuera - UNIB)

Acerca disso, é possível verificar que há princípios que regem a aplicação e proteção das normas referentes ao meio ambiente, tais como o princípio da prevenção, da precaução e o do poluidor-pagador, onde é possível o transporte e adaptação destas à seara trabalhista, sempre com vista a mitigação dos atos que importem em ofensa ao bem jurídico tutelado e, também, como forma de punição dos infratores que não respeitem ou não zelem pela integralidade e sanidade deste, sendo esse um dever do empregador, o qual pode responder de forma objetiva pelos danos.

Ademais, o tema em questão tem recebido destaque, inclusive, pela própria Organização Internacional do Trabalho que, através das convenções internacionais 155 e 161, que justificam a importância de seu estudo.

Acerca do entendimento a respeito do meio ambiente do trabalho, Barros (2013, p. 1036) o define como sendo:

[...] local onde o homem obtém os meios para prover a sua subsistência, podendo ser o estabelecimento empresarial, o ambiente urbano, no caso dos que executam atividades externas e, até o domicílio do trabalhador, no caso do empregado a domicílio.

Ou seja, por se tratar de direito fundamental e também em decorrência do princípio da dignidade da pessoa humana, impende ressaltar que a convergência deste tema para o credenciamento em tal categoria de direitos, destacando o fato da existência que decorre da possibilidade de inserção social do homem na sociedade, além de representar possibilidade de sua subsistência e o de sua família, podendo ser classificado como um direito metaindividual.

Ainda, em relação a proteção ao meio ambiente do trabalho, além desta classificação que diferencia a importância de tal política, seu caráter dúplice, ou seja, além de ser um metaindividual, também é um direito social, justamente pelos motivos já acima elencados.

Nesse sentido, Gosdal (2007, p. 116) afirma:

A existência digna está ligada ao princípio da valorização do trabalho. $\mathrm{O}$ acesso a um trabalho decente, em condições aceitáveis e justamente remunerado, transcende o âmbito puramente individual, alcançando a ordem 
Personalidade Acadêmica Homenageada:

Carlos Aurélio Mota de Souza (Universidade Ibirapuera - UNIB)

pública e o interesse coletivo.

Feitas tais considerações, um dos efeitos que decorrem da promoção de um meio ambiente do trabalho equilibrado é a necessidade de o empregador adotar uma política preventiva que vise a erradicar ou mitigar fatores e agentes que possam causar acidentes ou doenças do trabalho, os quais, dentre eles, podemos verificar práticas de assédio moral.

Assim é que nas relações de trabalho, travadas dentro de uma empresa, denota-se uma premente necessidade de obtenção de lucro. Nesse sentido, muitas empresas, desconsiderando a proteção ao meio ambiente do trabalho, passaram a desenvolver diversos métodos de gestão, primando apenas pelo atendimento ao seu objetivo único - obtenção de lucro.

Desta maneira, várias práticas e métodos de gestão tem sido adotados tomando como paradigma apenas a obtenção de lucro a qualquer custo, o que acaba ocasionando condutas relacionadas com práticas irregulares ou ilegais, entre elas àquelas ligadas a práticas abusivas ou de assédio moral.

Nas palavras de Stadler (2008, p. 69), o assédio moral pode ser definido como:

O assédio moral constitui-se em fenômeno que consiste na exposição dos trabalhadores e trabalhadoras (quando o assédio ocorre no ambiente de trabalho) a situações humilhantes e constrangedoras, repetitivas e prolongadas durante a jornada de trabalho e no exercício de suas funções. Ele é mais comum em relações hierárquicas autoritárias e assimétricas, em que predominam condutas negativas, relações desumanas de longa duração, de um ou mais chefes dirigidas a um ou mais subordinados, atitudes essas que desestabiliza a relação da vítima com o ambiente de trabalho e a organização, forçando-a a desistir do emprego.

Hirigoyen (2006, p. 67) conceitua a referida conduta como sendo:

Uma sequência de comportamentos deliberados por parte do agressor destina-se a desencadear a ansiedade da vítima, o que provoca nela uma atitude defensiva, que é, por sua vez, geradora de novas agressões. Depois de certo tempo de evolução do conflito, surgem fenômenos de fobia recíproca: ao ver a pessoa que detesta, surge no perseguidor uma raiva fria, desencadeia-se na vítima uma reação de medo. É um reflexo condicionado 
Personalidade Acadêmica Homenageada:

Carlos Aurélio Mota de Souza (Universidade Ibirapuera - UNIB)

\begin{abstract}
agressivo e defensivo. O medo provoca na vítima comportamentos patológicos, que servirão de álibis para justificar retroativamente a agressão. Ela reage, na maior parte das vezes, de maneira veemente e confusa. Qualquer iniciativa que tome, qualquer coisa que faça, é voltada contra ela pelo perseguidor. O objetivo de tal manobra é transformá-la, levá-la a uma total confusão que a faça cometer erros.
\end{abstract}

Acerca dos meios de manifestação do assédio moral, é possível identificar quatro categorias: a deterioração proposital das condições de trabalho, o isolamento e a recusa da comunicação, atentados contra a dignidade da vítima e as formas de violência (verbal, física ou sexual).

No mesmo sentido, há três formas principais de manifestação da conduta abusiva: assédio perverso (que consiste em perseguições de ordem predominantemente individual), assédio estratégico (situação que visa incitar o pedido de desligamento do empregado) e o organizacional (consistente na implementação de métodos empresariais visando a obtenção de resultados mediante práticas de condutas que dividem, aloquem ou hierarquizem o trabalho, tornando-o um calvário para a vítima).

Esse último tipo, por ser sui generis, merece estudo destacado, tendo em vista que importa em imposição de métodos e formas de gestão que acabam por minar ou diminuir a autoestima do empregado ao ponto de torná-lo portador de doenças ocupacionais ou fazendo com que a vida do empregado na organização resulte impraticável.

Acerca de tais métodos podem ser citados, como exemplos, a definição de metas impossíveis de serem alcançadas ou inatingíveis, ou, ainda, com a estipulação de critérios obscuros, além de controles excessivos dos recursos, bem como de pressões sistemáticas e de ameaças reiteradas de demissão ou mesmo de retaliação, sempre buscando que a vítima obtenha rentabilidade a qualquer custo.

Por tais práticas, verificam-se efeitos deletérios à vida da vítima, o que é abordado por Alves (2013, p. 99):

[...] o processo de 'captura' da subjetividade do trabalho como inovação socioambiental tende a dilacerar (e estressar) não apenas a dimensão física da corporalidade viva da força de trabalho, mas sua dimensão psíquica e 
Personalidade Acadêmica Homenageada:

Carlos Aurélio Mota de Souza (Universidade Ibirapuera - UNIB)

espiritual, que se manifesta por sintomas psicossomáticos.

Reafirmando os efeitos causados à vítima, podemos citar, ainda, a definição de Pohlmann (2014, p. 57):

\begin{abstract}
A violência aplicada coletivamente como estratégia gerencial não é tão percebida quanto a violência promovida individualmente ou a um grupo específico, razão pela qual, geralmente, apenas a partir do momento em que há uma intersecção entre o dano promovido coletivamente e o dano à esfera do sujeito (s) identificável (is) é que costumam ser contestados determinados mecanismos fundamentados no assédio moral organizacional. No entanto, a fixação do problema na (s) vítima (s) da violência específica ou na figura do (s) agressor (es) desvia a tenção do viés coletivo do problema.
\end{abstract}

Fato é que o assédio moral organizacional ganha contornos cada vez mais cruéis na medida em que sua comprovação não é simples de ser feita, tendo em vista a ausência de elementos mais palpáveis de prova que autorizem a referida conclusão, bem como de ser tênue o limite entre a estipulação de práticas gerenciais - tais como definição de meta, por exemplo - com a abusividade de tais condutas, além de se tratar de elemento que importa em análise subjetiva de quem o investiga.

Denota-se, assim, a ligação umbilical existente entre o meio ambiente do trabalho, que deve ser equilibrado e hígido, com a necessidade de se evitar e combater a presença de agentes e elementos que tornem a convivência nesse plano insustentável a ponto de tornar de eliminar ou acabar com autoestima e saúde da vítima.

Nesse particular, Ebert (2012, p. 1334) afirma:

O conceito de meio-ambiente assumido pelo ordenamento jurídico pátrio no art. 224, caput, da Carta Magna e no art. $3^{\circ}$ da Lei ํㅡ 6.938/81 compreende a totalidade dos elementos materiais e imateriais que circundam os seres humanos e são essenciais para a manutenção de sua integridade física, bem como de sua qualidade de vida [...]. Sendo o conceito de meio-ambiente assumido pelo ordenamento jurídico onipresente e estando ele vinculado umbilicalmente à ideia de dignidade humana, não há como afastar de seu âmbito de incidência os locais de trabalho.

Feita a necessária explanação acerca do meio ambiente do trabalho, como 
Personalidade Acadêmica Homenageada:

Carlos Aurélio Mota de Souza (Universidade Ibirapuera - UNIB)

elemento da dignidade humana do trabalhador, observado ainda sob sua faceta de obrigação imposta ao empregador de sua preservação, bem como de condutas e comportamentos abusivos, incluindo o assédio moral, denota-se a necessária forma de combate-lo, servindo o fomento, a instituição e a implementação de uma forte política de conformidade como meio para atingir a matriz constitucional de dignidade da pessoa humana e do valor social do trabalho.

\section{A POLÍTICA DE CONFORMIDADE: COMPLIANCE. CONCEITOS E CARACTERÍSTICAS}

Com a modificação dos mercados, o processo de globalização mais acentuado e a maior abertura destes, com a instituição de uma política concorrencial, inclusive prevista na Constituição Federal, verificou-se a necessidade de elaboração de regras mais claras e mais rígidas para mitigação e erradicação de práticas desleais e de medidas que tentem banir ou minimizar atos de corrupção.

Por se tratar de um tema de grande preocupação e relevância, a corrupção é abordada e combatida inclusive pela Organização das Nações Unidas (ONU) que, através de seu órgão denominado UNODC (Escritório contra Drogas e Crimes), que editou, em setembro de 2003, a Convenção das Nações Unidas contra a Corrupção, a qual é definida como sendo:

[...] práticas de suborno e de propina, a fraude, a apropriação indébita ou qualquer outro desvio de recursos por parte de um funcionário público. Além disso, pode envolver casos de nepotismo, extorsão, tráfico de influência, utilização de informação privilegiada para fins pessoais e a compra e venda de sentenças judiciais, entre diversas outras práticas.

Importante ressaltar que a instituição do compliance decorre da ideia de ética nas relações, o que é definido e asseverado por Séllos-Knoerr e Bega (2013, p. 462) asseveram: 
Personalidade Acadêmica Homenageada:

Carlos Aurélio Mota de Souza (Universidade Ibirapuera - UNIB)

\begin{abstract}
O agir ético empresarial é ato volitivo corporativo e para uma empresa, manter-se dentro da ética construída por ela mesma traz muitos benefícios como por exemplos: custos menores, a possibilidade de avaliar com precisão - desempenho da sua estrutura, legitimidade moral para exigir comportamento ético dos empregados, geração de lucro livre de contingências, a obtenção de respeito de parceiros comerciais, dentre outros benefícios.
\end{abstract}

A par de tais considerações, temáticas como código de ética e governança passaram a fazer parte do vocabulário e do cotidiano das organizações que, visando preservar a sua imagem, passaram a adotar novas ferramentas para auxílio em sua gestão, tanto externa como interna, com escopo de superação apenas da ideia simplesmente do lucro, mas do atendimento a busca da função social.

Dentre a essas novas ideias, além das exigências externas (tais como instituição de "selos" e de medidas que tem por finalidade banir concorrentes desleais), internamente surgem normas que tem por escopo disciplinar e positivar condutas não aceitas com o intuito de eliminar concorrentes, podendo ser citada as Leis $n^{\circ}$ 12.529, de 30 de novembro de 2011 (lei de defesa da concorrência) e 12.846, de $1^{\circ}$ de agosto de 2013 (lei anticorrupção).

Com o advento das referidas normas, verificou-se a positivação de comportamentos que devem ser inibidos - e evitados - pelas corporações, tais como os atos de corrupção, que abrangem tanto empregados como diretores, além de uma maior necessidade de criação de controles e regulamentos no tocante a negociação com a Administração Pública e em relação aos particulares.

Nesse particular, como mecanismo de controle e atendimento das exigências legais, as corporações passaram a criar diversos elementos que auxiliam no controle das decisões de seus integrantes e diretores, tais como elaboração de códigos de ética e conduta, além da contratação de auditorias externas e independentes, tudo com o escopo de evitar a exposição a penalidade legais e redução de outros riscos.

É nesse cenário que se insere a criação e instituição de políticas de conformidade, mais como conhecida como compliance, sendo esse um instrumento de mitigação e combate a atos que podem ser considerados irregulares ou ilícitos, visando prevenir riscos e adversidades advindas de tais práticas. 
Personalidade Acadêmica Homenageada:

Carlos Aurélio Mota de Souza (Universidade Ibirapuera - UNIB)

Ribeiro e Diniz (2014, p. 88) apresentar também uma definição de compliance, conforme se verifica abaixo:

Compliance é uma expressão que se volta para as ferramentas de concretização da missão, da visão e dos valores de uma empresa. (...). Será instrumento responsável pelo controle de riscos regulatórios e de reputação, devendo tal função ser exercida pelo Compliance Officer, o qual deve ser independente e ter acesso direto ao Conselho de Administração.

Nas palavras de Breier (2013), pode-se entender compliance como sendo:

[...] estar em conformidade, colocando em prática regulamentos internos e externos, tendo como objetivo a mitigação de riscos e prejuízos, principalmente no âmbito empresarial, mas sendo também aplicado, e cada vez com maior intensidade, na esfera pública.

O referido órgão tem como finalidade garantir a conformidade das práticas adotadas pela organização em relação aos atos de seus empregados, gestores e administradores, visando prevenir a prática de ilegalidades, além do cumprimento dos regulamentos e normas adotadas pela empresa, não se prestando somente a proteção interna, mas também para consumidores e investidores.

Verifica-se, portanto, que a instituição de uma política de conformidade ou compliance tem por finalidade gerenciar riscos relacionados com punições legais, bem como mitigar prejuízos financeiros e de imagem decorrentes de descumprimentos de normas e/ou regulamentos e códigos de conduta.

Do exposto, se extrai que a implantação de um programa de compliance em uma organização empresarial vai muito além do cumprimento da legislação, mas demonstra a transparência e a importância desta para com comportamentos éticos e morais, que ecoa não somente no âmbito interno, mas também para elementos externos, tais como investidores e consumidores.

Acerca do assunto, Coimbra e Manzi (2010, p. 5) dizem que: 
Personalidade Acadêmica Homenageada:

Carlos Aurélio Mota de Souza (Universidade Ibirapuera - UNIB)

\begin{abstract}
O compliance é uma estratégia não apenas voltada a obter ganho de valor e competitividade em longo prazo, mas também contribui decisivamente para a própria sobrevivência da organização. (...) O sucesso das organizações é extremamente dependente da admiração e da confiança pública, refletida no valor de suas marcas, na sua reputação, na capacidade de atrair e fidelizar clientes, investidores, parceiros e até os empregados.
\end{abstract}

Ocorre, entretanto, que a implementação de um programa de conformidade em uma organização não é simples, e deve levar em consideração as peculiaridades das corporações, em que pese possa ser adotado tanto em grandes empresas ou não, devendo ser de adesão voluntária e "[...] ser percebido e internalizado pelos colaboradores da organização, aceito como parte de seu conjunto de valores que o fundamenta e tornar-se o guia das ações da empresa e de seus funcionários." (Giovanini, 2014, p. 50).

Como característica geral, o programa deve ser voltado para prevenção, detecção e correção de condutas que não estejam ou sejam conformes com o estipulado em legislação, normas, regulamentos e códigos de éticas, devendo ser definidos quais são os atos a serem objeto de tal investigação.

Há, ainda, outra forma de compliance que é àquele voltado para o ciclo de planejamento, execução, controle dos atos e na verificação de tais planos com a concatenação dos resultados obtidos, mais conhecido como ciclo de melhoria contínua.

Nesse sentido, Giovanini (2014, p. 50-52) pontua:

\begin{abstract}
Foco na prevenção é o modelo que engloba primeira e principalmente a prevenção de condutas não-conformes, considerando a realidade empresarial e a imprevisibilidade das situações que possam surgir, também engloba a detecção de eventuais atos não-conformes, bem como, ações corretivas para atos que não estejam em compliance. Tripé deste modelo: prevenção, detecção e correção. O principal pilar é a prevenção, devendo instituir-se políticas e procedimentos claros para todas as situações de risco, conjugados ao respectivo treinamento de funcionários. A deteç̧ão é composta por "controle" (análise periódica dos processos adotados) e por "canais de acesso" (canal de comunicação com os stakeholders). Detectada alguma inconformidade, passa-se a buscar sua correção.
\end{abstract}

E continua o autor: 
Personalidade Acadêmica Homenageada:

Carlos Aurélio Mota de Souza (Universidade Ibirapuera - UNIB)

\begin{abstract}
Melhoria contínua é o modelo focado no ciclo PDCA - Plan, Do, Check e Act - o planejamento por parte da equipe de compliance das políticas e planos a seguir, a execução do referido plano, o controle dos processos instituídos e a compilação das três outras fazes no agir, ou seja, momento em que se melhoram as políticas ou se aplicam penalidades, se for o caso.
\end{abstract}

Acerca dos elementos que devem constituir um programa de compliance, Coimbra e Manzi (2010, p. 54) citam os seguintes:

\begin{abstract}
a) padrões de conduta e política e procedimentos escritos; b) designação de um compliance Officer e/ou um Comitê de Compliance; c) educação e treinamento para fornecer conhecimento de forma efetiva; d) canal de comunicação anônima de eventuais problemas de compliance; e) monitoramento proativo de processos específicos e documentados para fins de compliance e ajuda na redução de problemas identificados; f) comunicação efetiva; g) ações disciplinares; e, h) ações corretivas.
\end{abstract}

Além de tais elementos e exigências, é necessário que a comunicação seja clara e direcionada a todos os integrantes, bem como o compliance officer tenha liberdade para atuação, além de necessariamente ser um órgão independente e atuante.

Feitos os esclarecimentos, é possível notar que a aplicação de política de conformidade também tem abrangência e aplicação no âmbito trabalhista, tanto para diretores quanto para empregados, sempre visando evitar práticas deletérias ou que possam vir a comprometer o ambiente de trabalho e/ou a imagem da corporação perante terceiros, investidores e consumidores.

No que diz respeito a seara trabalhista, é possível notar que sua plena aplicabilidade, pois a estipulação de políticas de gestão com o único objetivo a obtenção do lucro acaba por gerar tratamentos e condutas abusivas e que acarretam prejuízos físicos e mentais aos empregados ou, ainda, quando esses atuam em desrespeito às normas e regulamentos da empresa.

Destas condutas, a mais comum é o assédio moral praticado no ambiente de trabalho, sempre com o intuito do atingimento de metas, com a prática de cobranças insistentes e abusivas ou, ainda, com intuito de perseguição, gerando um total descompasso e desrespeito às normas, ocasionando um ambiente de trabalho 
Personalidade Acadêmica Homenageada:

Carlos Aurélio Mota de Souza (Universidade Ibirapuera - UNIB)

cáustico, além de ocasionar outros prejuízos, tais como queda de produtividade, afastamentos de empregados e mácula da imagem.

Tais considerações e pontuados os objetivos e amplitude da elaboração e implantação de um programa de compliance em uma empresa, é necessário agora identificar em que medida tal atividade pode ser benéfica para organização, mais especificamente no combate às formas e condutas abusivas que constituem o assédio, o que será feito no capítulo seguinte.

\section{COMPLIANCE COMO INSTRUMENTO DE PREVENÇÃO E COMBATE AO ASSÉDIO MORAL NAS RELAÇÕES DE TRABALHO}

Conforme esclarecido nos tópicos anteriores, as empresas devem ter condutas pautadas pela transparência e objetividade, não só por conta da preservação de sua imagem perante terceiros e investidores, mas também em razão da preservação do clima organizacional praticado no ambiente de trabalho e das relações daí advindas com os seus empregados.

O compliance guarda estreita relação com a ética e a moral, pois visa preservar condutas coerentes com normativos e regulamentos adotados pela empresa. Nesse sentido, Comparato (2006, p. 23) descreve:

\footnotetext{
O sistema ético em vigor na sociedade exerce sempre a função de organizar ou ordenar a sociedade, em vista de uma finalidade geral. Não existe ordem social desvinculada de um objetivo último, pois é justamente em função dele que se pode dizer se o grupo humano é ordenado ou desordenado; se se está diante de uma reunião ocasional de pessoas, ou de uma coletividade organizada.
}

Conforme já explanado, o assédio moral, em suas mais variadas formas, acaba causando não só prejuízos de ordem financeira, tais como danos à imagem e queda de produtividade, mas também de ordem imaterial, tais como o afastamento de empregados por conta de problemas de saúde mental pela prática reiterada de condutas abusivas ou cobranças insistentes e desmedidas. 
Personalidade Acadêmica Homenageada:

Carlos Aurélio Mota de Souza (Universidade Ibirapuera - UNIB)

Desta maneira, ao evitar tais práticas, a empresa pode lançar mão de diversos instrumentos, tais como consultorias, pesquisas de opinião, programas de ombudsman entre empregados, telefones para denúncia de condutas desleais. Fato é que o compliance pode ser incluído nesse rol, com alguns diferenciais que o tornam, além de uma inovação, um instrumento muito eficaz no combate a condutas desleais e prejudiciais, conforme já demonstrado.

Muito além do aspecto econômico, o compliance tem como principal característica a prevenção, seja de crimes ou ilegalidades ou mesmo condutas que ofendem a ética.

Assim, o primeiro efeito causado na instituição de um programa de conformidade, quando este obedece a todos os requisitos traçados acima, é o efeito pedagógico e psicológico que causa internamente entre os empregados e ocupantes de cargos de chefia na organização, tendo em vista a percepção geral da existência de condutas éticas e morais que devem ser praticadas e respeitadas na empresa.

Verifica-se, dessa forma, que a conformidade pode ser obtida com a utilização de diversos instrumentos, tais como a criação de um código de ética e conduta, o qual deve ser claro e objetivo, deve ter ampla divulgação, ser dirigido a todos os empregados e ocupantes de cargos de chefia dentro da organização, ou seja, sua aplicação deve ser geral e indistinta, com descrição das condutas moral e eticamente valorizadas e incentivadas pela empresa.

Acerca de tal instrumento, tal como auxiliar do compliance, e relativamente ao assédio moral pessoal ou organizacional, é necessário que se preveja condutas que serão abordadas, além do estabelecimento e informação dos canais pelos quais o empregado pode se utilizar para ver mitigado e até mesmo erradicado tais condutas que possam ser porventura adotadas por algum gestor.

Deste particular, outro instrumento apto a auxiliar no combate ao assédio moral e, por sua vez, na conformidade dos comportamentos, é a instituição de um canal de denúncias, o qual deve preservar o anonimato da fonte que 0 utiliza, garantindo assim a lisura da apuração e a confidencialidade do procedimento, evitando constrangimentos e retaliações por parte do denunciado. 
Personalidade Acadêmica Homenageada:

Carlos Aurélio Mota de Souza (Universidade Ibirapuera - UNIB)

Tais denúncias devem ser dirigidas ao compliance officer que, por sua vez, deve trata-las com total atenção e prioridade, sempre com a preservação da identidade do denunciante, com intuito de que seja apurada a existência dos elementos informados, bem assim da procedência ou não de tais irregularidades. Em sendo verificada a ocorrência de tais fatos, faz-se necessário a sugestão de medidas a serem aplicadas, além da apuração séria e rápida de tais condutas.

No mesmo sentido, ultrapassada a confirmação da ocorrência da ilegalidade ou irregularidade, faz-se necessário, por parte do compliance officer e, por sua vez, da organização, a adoção de medidas corretivas e preventivas, visando que a citada prática não volte mais a ocorrer. Cumpre destacar que a tomada de tais medidas preventivas não elide àquelas de natureza disciplinar, dirigidas ao agressor/assediador, que devem ser aplicadas por quem detém tais prerrogativas.

Ainda, também funciona como meio a estimular a atuação e conhecimento da política de compliance a instituição e prática de treinamentos constantes por parte da empresa aos seus empregados, sempre com escopo de demonstrar as regras existentes e a forma de cumpri-las, bem como informar quais são as condutas que devem ser repudiadas e não toleradas na organização, sejam por parte de empregados ou de ocupantes de cargos de chefia.

Ocorre, entretanto, que não basta apenas a adoção de tais medidas por parte dos responsáveis pela política de conformidade, sendo necessário que a organização sempre faça o acompanhamento e estabelecimento de planos de ação visando verificar a efetividade não só das medidas, mas também do responsável pela prevenção de tais atos e se os reflexos obtidos geraram os impactos esperados, tais como erradicação da conduta abusiva.

Assim, com um programa de conformidade atuante e eficiente, os reflexos esperados vão além dos monetários, acarretando no fomento de um ambiente de trabalho ético, equilibrado e hígido.

Nesse particular, Ribeiro e Diniz (2014, p. 90) pontuam: 
Personalidade Acadêmica Homenageada:

Carlos Aurélio Mota de Souza (Universidade Ibirapuera - UNIB)

no mercado. Assim, alcançará altos níveis de cooperação interna e externa, com o consequente aumento de lucro, mas sempre de forma sustentável, trazendo benefícios à organização, a seus empregados e à sociedade.

Por conseguinte, conforme previsto na Constituição Federal, em seu artigo 1ํㅡ, incisos III e IV², que tem no trabalho um fundamento da República, devendo ser preservado como elemento de dignificante da pessoa humana, com respeito em seu valor social, ou seja, de modificação e transformação de toda uma sociedade.

É nesse sentido que não se admitem mais condutas abusivas ou que se constituam em assédio, assim como atos de corrupção, tendo em vista que tais práticas vilipendiam não só os direitos dos envolvidos, mas também de toda uma sociedade, a qual se vê desrespeitada na ausência de transparência e comprometimento.

Importante ressaltar que o programa de compliance, como já dito anteriormente, pode representar mais do que dividendos, importando o respeito às normas e regulamentos instituídos, além de demonstrar transparência e seriedade de uma organização para com seus empregados e investidores.

Acerca dos efeitos da instituição de uma política de conformidade, importante citar a definição atribuída por Coimbra e Manzi (2010, p. 22):

Do ponto de vista macro, não se pode perder de vista que uma sociedade composta por organizações íntegras constitui constitui-se uma sociedade mais justa, harmoniosa, com maior respeito aos direitos individuais, com menos corrupção e pobreza. Assim, o compliance não protege apenas a organização em si, mas a sociedade como um todo. Ademais, o respeito às leis é um dos pilares centrais do Estado Democrático de Direito. A falta de integridade é fator de perda de confiança nas organizações, afetando ainda a economia nacional.

Assim, o programa de compliance funciona não só como meio para obtenção de respeitabilidade e fortalecimento da imagem de uma companhia, mas também para demonstração de confiabilidade perante terceiros e internamente, pois preserva a

\footnotetext{
${ }^{2}$ Art. 1ํㅡ A República Federativa do Brasil, formada pela união indissolúvel dos Estados e Municípios e do Distrito Federal, constitui-se em Estado Democrático de Direito e tem como fundamentos: [...] III - a dignidade da pessoa humana; IV - os valores sociais do trabalho e da livre iniciativa; [...]
} 
Personalidade Acadêmica Homenageada:

Carlos Aurélio Mota de Souza (Universidade Ibirapuera - UNIB)

saúde de empregados, além de destacar o fato de que os valores e a cultura da organização, encontram-se em sintonia com os anseios da sociedade.

Pelo exposto, verifica-se a necessidade da implementação de um programa de conformidade nas organizações, com o intuito de que seja adotada uma nova cultura não só da empresa, seguindo os moldes de respeito às normas e regulamentos, além da abolição de condutas irregulares ou ilegais por parte dos envolvidos, sejam pessoas jurídicas, empregados ou terceiros que com ela se relacionem.

\section{CONCLUSÃO}

Com o referido trabalho, procurou-se demonstrar em que medida a adoção e a instituição das políticas de conformidade nas empresas pode contribuir na mitigação ou, até mesmo, na erradição das práticas de assédio moral como método de gestão, tudo com intuito de preservação não só da imagem da organização e da produtividade dos empregados, mas também na manutenção e no atendimento de um meio ambiente de trabalho hígido e sadio, posto que tal é obrigação do empregador.

O estudo, assim, foi elaborado procurando abordar cada um dos elementos aqui propostos, visando demonstrar a particularidade destes, além de especificar e ressaltar a importância de tais componentes, bem como da verificação dos malefícios e a redução dos riscos aos quais estão expostas as empresas, os empregados e os consumidores.

Houve a necessidade, como forma de contextualizá-los, de utilizar de descrições conceituais acerca de cada um deles, visando, com isso, demonstrar a exata noção e amplitude destes na atualidade, além da necessária demonstração de sua recorrência no cotidiano das organizações.

Destacou-se, através de uma pesquisa bibliográfica sobre o tema, a importância e a necessidade de elaboração e implantação de um programa de conformidade e os efeitos causados por tal prática, na medida em que os benefícios 
Personalidade Acadêmica Homenageada:

Carlos Aurélio Mota de Souza (Universidade Ibirapuera - UNIB)

são inegáveis, tendo em vista que preserva não somente a imagem de toda uma corporação, mas também erradica ou minimiza a prática de assédio moral, contribuindo para manutenção de um ambiente de trabalho equilibrado, cumprindo desta maneira a matriz constitucional de valorização do trabalho e, por conseguinte, a dignidade da pessoa humana do trabalhador.

Ainda, por se tratar de um fenômeno relativamente novo na cultura organizacional nacional, foi necessário abordar os elementos que podem ser aplicados como forma de realização do compliance, e de que maneira este pode atuar dentro de uma organização.

Por fim, com o presente artigo, buscou-se destacar a importância de um novo formato de organização às empresas, com escopo na busca por boas práticas e medidas que combatam métodos de gestão abusivos, preservando assim o direito dos empregados e a imagem das companhias, além da sua importância ética na implementação e adoção de novas posturas exigidas pela sociedade.

\section{REFERÊNCIAS}

ALVES, Giovanni. Dimensões da precarização do trabalho: ensaios de sociologia do trabalho. Bauru: Canal 6, 2013.

BARROS, Alice Monteiro de. Curso de Direito do Trabalho. $9^{a}$ edição, São Paulo: LTR, 2013.

BRASIL. Constituição Federal. Disponível em: < http://www.planalto.gov.br/ccivil_03/Constituicao/Constituicao.htm>. Acesso em: 31 jul.2018.

Lei 6.938, de 31 de agosto de 1981. Disponível em: < http://www.planalto.gov.br/CCivil_03/leis/L6938compilada.htm>. Acesso em 2 ago.2018.

BREIER, Ricardo. Autorregulação impacta direito penal empresarial. Revista Consultor Jurídico. disponível em <http://www.conjur.com.br/2013-set28/autorregulacao-produzimpactos-direito-penal-empresarial\#author $>$. Acesso em 31 de julho 2018. 
Personalidade Acadêmica Homenageada:

Carlos Aurélio Mota de Souza (Universidade Ibirapuera - UNIB)

COIMBRA, Marcelo de Aguiar; BINDER, Vanessa Alessi Manzi (organizadores). Manual de compliance: preservando a boa governança e a integridade das organizações. São Paulo: Atlas, 2010.

COMPARATO, Fábio Konder. Ética: direito, moral e religião no mundo moderno. 2. ed. São Paulo: Companhia das Letras, 2013.

EBERT, Paulo Roberto Lemgruber. Meio ambiente do trabalho: conceito, responsabilidade civil e tutela. São Paulo: Revista LTR, v. 76, 2012.

GIOVANINI, Wagner. Compliance: a excelência na prática. 1ª Ed. São Paulo: 2014.

GOSDAL, Thereza Cristina. Dignidade do trabalhador: um conceito construído sob o paradigma do trabalho decente e da honra. São Paulo: LTr, 2007.

HIRIGOYEN, Marie-France. Mal-estar no trabalho: redefinindo o assédio moral. $2^{\mathrm{a}}$ edição. Rio de Janeiro: Bertrand Brasil, 2005.

POHLMANN, Juan Carlos Zurita. Assédio Moral Organizacional: identificação e tutela preventiva. São Paulo: LTr, 2014.

RIBEIRO, Marcia Carla Pereira; DINIZ, Patrícia Dittrich Ferreira. Compliance e Lei Anticorrupção nas Empresas. Revista de Informação Legislativa/Senado Federal, Subsecretaria de Edições Técnicas, Ano 50, n. 199, publicada pela Coordenação de Edições Técnicas, 2014.

STADLER, Denise de Fátima. Assédio moral: uma análise da teoria do abuso de direito aplicada ao poder do empregador. São Paulo: LTr, 2008.

SÉLLOS-KNOERR, Viviane Coêlho de; BEGA, Patrícia Fernandes. O agir ético na sociedade de consumo como desafio à atividade empresarial. Disponível em: $<$ http://revista.unicuritiba.edu.br/index.php/RevJur/article/viewFile/696/522>. Acesso em 8 ago. 2018.

UNODC. UNODC e corrupção. Disponível em <https://www.unodc.org//pobrazil/ pt/corrupcao/index.html>. Acesso em 1 ago. 2018. 